\title{
Numerical Investigations on Characteristics of Stresses in U-Shaped Metal Expansion Bellows
}

\author{
S. H. Gawande, ${ }^{1}$ N. D. Pagar, ${ }^{2}$ V. B. Wagh, ${ }^{3}$ and A. A. Keste ${ }^{1}$ \\ ${ }^{1}$ Department of Mechanical Engineering, M. E. Society's College of Engineering, Pune, Maharashtra 411001, India \\ ${ }^{2}$ Department of Mechanical \& Materials Technology and Department of Technology, S.P. Pune University, Pune 411007, India \\ ${ }^{3}$ Department of Mechanical Engineering, G.S.M. College of Engineering, Pune, Maharashtra 411045, India
}

Correspondence should be addressed to S. H. Gawande; shgawande@yahoo.co.in

Received 5 May 2015; Revised 23 July 2015; Accepted 6 August 2015

Academic Editor: Yuanshi Li

Copyright (C) 2015 S. H. Gawande et al. This is an open access article distributed under the Creative Commons Attribution License, which permits unrestricted use, distribution, and reproduction in any medium, provided the original work is properly cited.

\begin{abstract}
Metal expansion bellows are a mechanical device for absorbing energy or displacement in structures. It is widely used to deal with vibrations, thermal expansion, and the angular, radial, and axial displacements of components. The main objective of this paper is to perform numerical analysis to find various characteristics of stresses in U-shaped metal expansion bellows as per the requirement of vendor and ASME standards. In this paper, extensive analytical and numerical study is carried out to calculate the different characteristics of stresses due to internal pressure varying from $1 \mathrm{MPa}$ to $2 \mathrm{MPa}$ in U-shaped bellows. Finite element analysis by using Ansys14 is performed to find the characteristics of U-shaped metal expansion bellows. Finally, the results of analytical analysis and finite element method (FEM) show a very good agreement. The results of this research work could be used as a basis for designing a new type of the metal bellows.
\end{abstract}

\section{Introduction}

Metal bellows are structural component in which a wavy shape is formed on the surface of a circular tube to introduce elastic property. Expansion joints used as an integral part of heat exchangers or pressure vessels shall be designated to provide flexibility for thermal expansion and also to function as a pressure-containing element. Normally metal bellows are used as an expansion joint in shell and tube heat exchanger. It deals with vibrations, thermal expansion, and angular, radial, and axial displacements of components. Its present applications are in $\mathrm{AC}$ equipment, industrial plants, hose pipes, vacuum systems, and aerospace equipment.

Limited amount of research work has been carried out by some researchers working in the area of the expansion joint for shell and tube heat exchanger. Their work has been reported by performing industrial survey (namely, Alfa Laval India Ltd., Pune) and exhaustive literature review through earlier published research work, journal papers, and technical reports. Many design formulae of bellows can be found in ASME code [1]. And the most comprehensive and widely accepted text on bellows design is the Standards of Expansion
Joint Manufactures Association, EJMA [2]. Number of pilot and test experiments have been performed for analysis of AM350 steel bellows by Shaikh et al. [3]. As bellows are exposed to marine atmosphere for more than 13 years which leads to pitting effect, hence the determination of dynamic characteristics of beam finite elements by manipulating certain parameters on commercial software was done by Broman et al. [4]. In comparison with semianalytical, methods have potential of considering axial, bending, and torsion degrees of freedom at the same time, and the rest are modeled by finite elements in which experimental results are also verified. The effect of the elliptic degree of $\Omega$-shaped bellows toroid on its stresses is investigated by Li [5]. In addition, Becht IV [6] has investigated the fatigue behavior of expansion joint bellows. The results of $\Omega$-shaped bellows with elliptic toroid calculated stresses correspond to experiments. The elliptic degree of $\Omega$-shaped toroid affects the magnitude of internal pressure-induced stress and axial deflection-induced stress. It especially produces a considerable effect on the pressure-induced stress. To maintain the fatigue life of toroid bellows, during manufacturing process toroid elliptic degree must be reduced. EJMA stresses for unreinforced bellows are 
evaluated by Becht IV [6]. Using linear axisymmetric shell elements parametric analysis is conducted. Finite element analysis is carried out using commercial code. Meridional stresses due to internal pressure and displacement are accurate. Bellows-forming process is done after evaluating effective parameters by Faraji et al. [7]. FEM results are compared with analytical solutions. Faraji et al. [8] used a commercial FEM code, ABAQUS Explicit, to simulate manufacturing process of metal bellows. Forming of different shapes of tubular bellows using a hydroforming process is proposed by Kang et al. [9]. The conventional manufacturing of metallic tubular bellows consists of four-step process: deep drawing, ironing, tube bulging, and folding. In their study, single-step tube hydroforming combined with controlling of internal pressure and axial feeding was proposed. These reviewed papers show that there is need for rigorous analysis and forming parameters of bellows. It is stated that the $\Omega$-shaped bellows have much better ability to endure high internal pressure than common U-shaped bellows. Metal bellows have wide applications in piping systems, automotive industries, aerospace, and microelectromechanical systems. Kang et al. [10] have developed a microbellows actuator using microstereo lithography technology. Numerous papers have dealt with various aspects of bellows except for forming process. Broman et al. [4] have determined dynamic characteristics of bellows by manipulating certain parameters of the beam finite elements. Jakubauskas and Weaver [11] have considered the transverse vibrations of fluid-filled double-bellows expansion joints. Jha et al. [12] have investigated the stress corrosion cracking of stainless steel bellows of satellite launch vehicle propellant tank assembly. Zhu et al. [13] have investigated the effect of environmental medium on fatigue life for U-shaped bellows expansion joints. However, few papers have shown the manufacturing process of the metal bellows. Wang et al. [14] have developed a new process for manufacturing of expansion joint bellows from Ti-6Al-4V alloys with high degree of spring back. Wang et al. [14] have used gas pressure instead of fluid pressure, because the process was done in high temperature ambient. Kang et al. [10] have investigated the forming process of various shapes of tubular bellows using a single-step hydroforming process. Lee [15] has carried out parametric study on some of the forming process parameters of the metal bellows by finite element only. He has mentioned that, in general, metal bellows are manufactured in four stages: deep drawing, ironing, tube bulging, and folding.

From the literature survey, it is seen that a number of researchers have worked on study and applications of different types of bellows under various working conditions, their comparison, and manufacturing processes, and few are working on fatigue life enhancement. But investigations on need for selection of proper material of bellows for given application, their proper design, stresses induction, fatigue life analysis, and prediction of failure and investigations on various characteristics of different bellows and vibration effect are essential.

\section{Problem Formulation and Objective}

As per literature and industrial survey, it is seen that bellows are one of the most important elements in the expansion joint

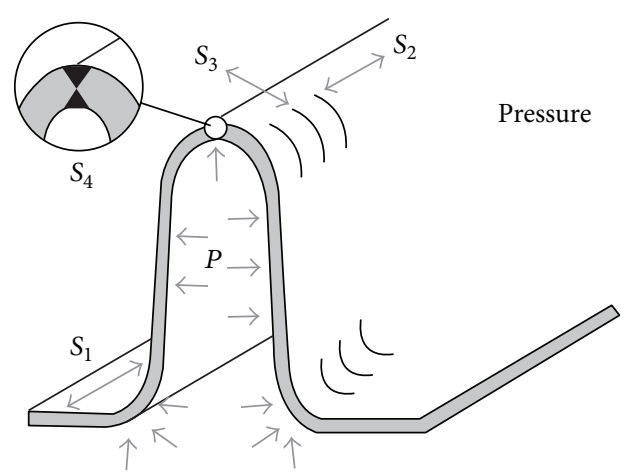

FIGURE 1: Stress directions in bellows.

and have the function to absorb regular as well as irregular expansion and contraction of the system. Bellows require high strength and good flexibility, which can be achieved by good design and proper manufacturing method. The design referred to from EJMA requires proper configuration selection which makes it difficult. The metal bellows are manufactured with different methods like forming, hydroforming, bulging, drawing, and deep drawing, which depend on applications. The materials used for bellows are normally stainless steel; in rare cases Inconel and aluminum are also used. Different shapes of bellows are U-shaped, semitoroidal, S-shaped, flat, stepped, single sweep, and nested ripple. As per discussion with experts working in the same field, it is observed that the concept of study in this paper needs detailed understanding of proper design and investigations on selection of materials, shapes, vibration effect, joining of bellows to shell, stresses, flow analysis, fatigue life analysis, and prediction of failure. Hence this work focuses on selection of materials of bellows for the given application, their proper design, and determination of characteristics of stresses of bellows, fatigue life analysis, and prediction of failure.

\section{Determination of Characteristics of Stresses of Bellows by Analytical Analysis}

Metal expansion bellows are a very distinctive component of a piping system. They must be designed strong enough to accommodate the system design pressure as well as flexible enough to accept the design deflections for a calculated number of occurrences, with a minimum resistive force. In order to understand the static and dynamic behavior of metal expansion bellows as shown in Figure 5, it is necessary to study the selection of materials of bellows for the given application, basic fundamental, their proper design, and working. The different mechanical properties and design parameters for bellows under consideration are shown in Table 1.

The design and analytical analysis of metal expansion bellows is performed as per ASME standards. Figure 1 shows the direction of different stresses induced in metal expansion bellows. According to ASME standards, the circumferential 
TABLE 1: Different design parameters.

\begin{tabular}{|c|c|c|}
\hline Design parameters & Notations & Specifications \\
\hline Expansion joint material & & SA-240 321 \\
\hline Material UNS number & & S32100 \\
\hline Bellows design allowable stress & $S$ & $129.65 \mathrm{~N} / \mathrm{mm}^{2}$ \\
\hline Bellows ambient allowable stress & $S_{a}$ & $137.89 \mathrm{~N} / \mathrm{mm}^{2}$ \\
\hline Bellows yield stress & $S_{y}$ & $157.39 \mathrm{~N} / \mathrm{mm}^{2}$ \\
\hline $\begin{array}{l}\text { Bellows elastic modulus at design } \\
\text { temp. }\end{array}$ & $E_{b}$ & $183090 \mathrm{~N} / \mathrm{mm}^{2}$ \\
\hline $\begin{array}{l}\text { Bellows elastic modulus at ambient } \\
\text { temp. }\end{array}$ & $E_{o}$ & $195121 \mathrm{~N} / \mathrm{mm}^{2}$ \\
\hline Poisson's ratio & $v_{b}$ & 0.300 \\
\hline Bellows material condition & & Formed \\
\hline $\begin{array}{l}\text { Design cycle life, required number } \\
\text { of cycles }\end{array}$ & $N_{\text {req }}$ & 7000 \\
\hline Design internal pressure & $P$ & $1.099 \mathrm{~N} / \mathrm{mm}^{2}$ \\
\hline $\begin{array}{l}\text { Design temperature for internal } \\
\text { pressure }\end{array}$ & & $190^{\circ} \mathrm{C}$ \\
\hline Bellow type & & U-shaped \\
\hline Bellows inside diameter & $D_{B}$ & $131.000 \mathrm{~mm}$ \\
\hline Convolution depth & $w$ & $8.000 \mathrm{~mm}$ \\
\hline Convolution pitch & Q & $8.000 \mathrm{~mm}$ \\
\hline $\begin{array}{l}\text { Expansion joint opening per } \\
\text { convolution }\end{array}$ & $\Delta Q$ & $0.2985 \mathrm{~mm}$ \\
\hline Total number of convolutions & $N$ & 10 \\
\hline Nominal thickness of one ply & $t$ & $0.300 \mathrm{~mm}$ \\
\hline Total number of plies & $n$ & 3 \\
\hline End tangent length & $L_{T}$ & $13.000 \mathrm{~mm}$ \\
\hline Fatigue strength reduction factor & $K_{g}$ & 1.500 \\
\hline
\end{tabular}

membrane stress $\left(S_{1}\right)$ in bellows tangent due to internal pressure is given as per

$$
\begin{aligned}
& S_{1} \\
& =\frac{1}{2}\left\{\frac{L_{t} \times E_{b} \times K \times P\left(D_{b}+n \times t\right)^{2}}{\left[n \times t \times\left(D_{b}+n \times t\right) \times L_{t} \times E_{b}+t_{c} \times D_{c} \times L_{c} \times E_{c} \times K\right]}\right\} .
\end{aligned}
$$

The end convolution circumferential membrane stress $\left(S_{2}\right)$ due to internal pressure based on the equilibrium considerations is as shown in Figure 2. Equation (2) represents the end convolution circumferential membrane stress:

$$
S_{2, E}=\frac{1}{2}\left\{\frac{\left[q \times D_{m}+L_{t} \times\left(D_{b}+n \times t\right)\right] \times P}{\left(A+n \times t_{p} \times L_{t}+t_{c} \times L_{c}\right)}\right\},
$$

where $D_{m}$ is mean diameter of bellows convolution and it is given as

$$
D_{m}=D_{b}+w+n \times t .
$$

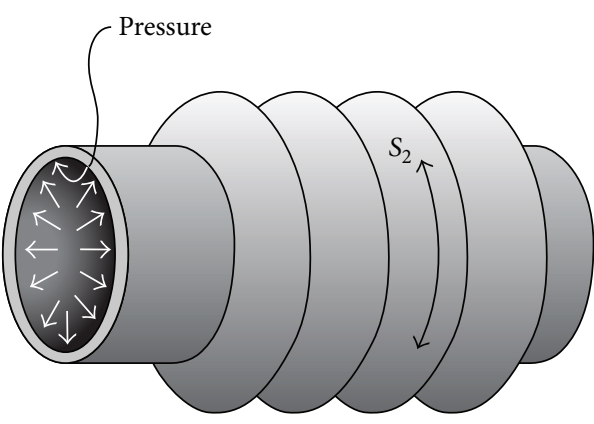

FIGURE 2: Deflection stresses acting on bellows.

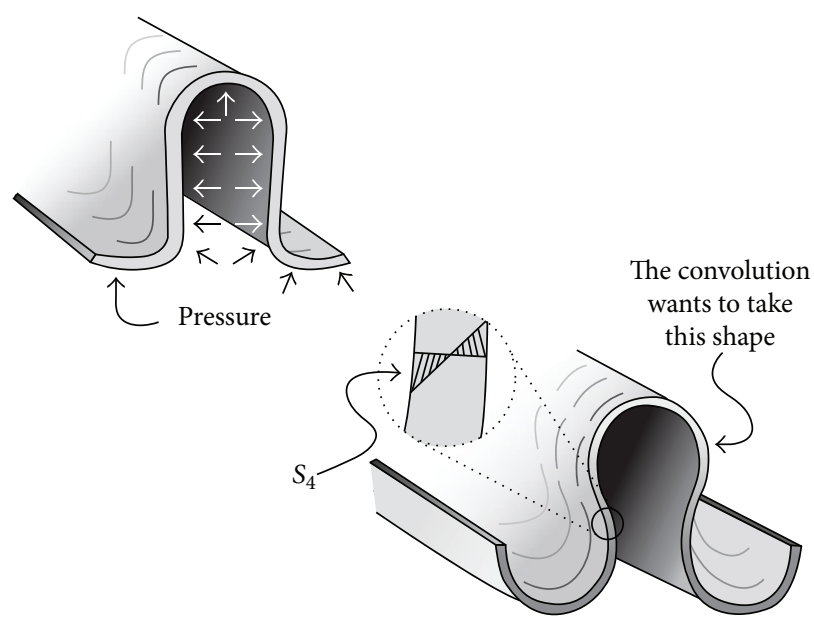

FIGURE 3: Meridional bending stress due to internal pressure.

The intermediate convolution circumferential membrane stress $\left(S_{2, I}\right)$ due to internal pressure is calculated by using the following equation:

$$
S_{2, I}=\frac{1}{2}\left\{\frac{P \times q \times D_{m}}{A}\right\} .
$$

The bellows meridional membrane stress $\left(S_{3}\right)$ due to internal pressure is calculated based on the component of pressure in axial direction acting on the convolution divided by the metal area of root and crown by using the following equation:

$$
S_{3}=\frac{1}{2}\left\{\frac{W \times P}{n \times t_{p}}\right\} \text {. }
$$

The bellows meridional bending stress $\left(S_{4}\right)$ due to internal pressure as represented in Figure 3 is given by (6). Figure 4 shows the variation of meridional bending stresses induced in bellows:

$$
S_{4}=\left\{\frac{1}{2 \times n}\right\} \times\left\{\frac{W}{t_{p}}\right\}^{2} \times P \times C_{p} .
$$

The bellows meridional membrane stress $\left(S_{5}\right)$ and meridional bending stress $\left(S_{6}\right)$ due to deflection are given by $(7)$. Figure 4 


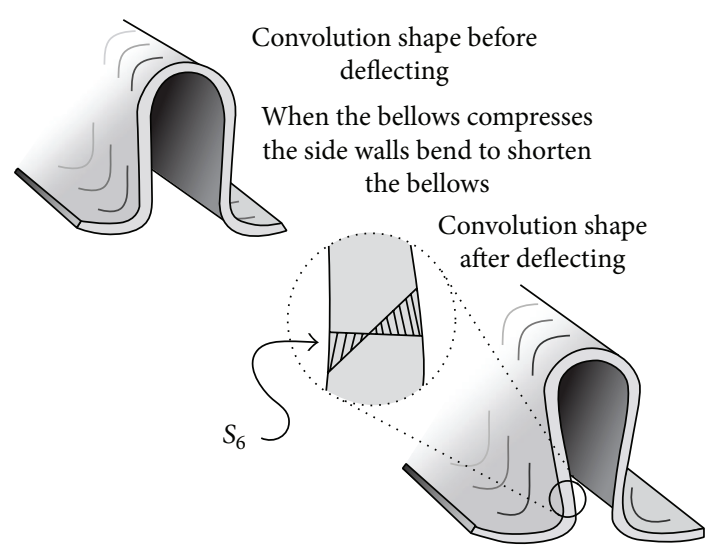

FIGURE 4: Meridional bending stress due to deflection.

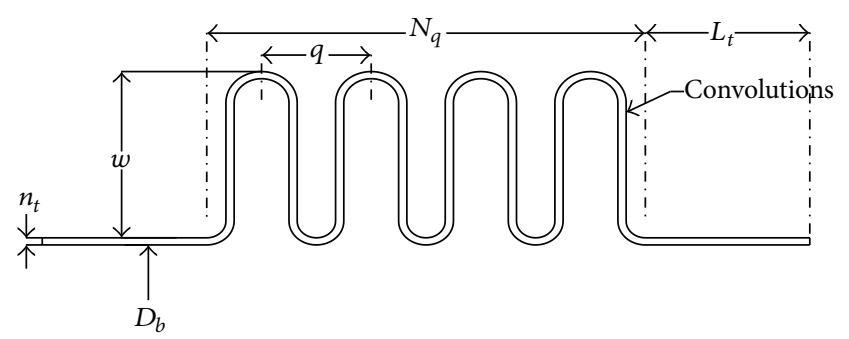

Figure 5: Geometry of metal expansion bellows.

shows the representation of meridional bending stress due to deflection. Consider

$$
\begin{aligned}
& S_{5}=E_{b} \times\left(t_{p}\right)^{2} \times \frac{\Delta Q}{\left(2 \times w^{3} \times C_{f}\right)}, \\
& S_{6}=5 \times E_{b} \times t_{p} \times \frac{\Delta Q}{\left(3 \times w^{2} \times C_{d}\right)},
\end{aligned}
$$

where $C_{p}, C_{f}$, and $C_{d}$ are the factors for calculating $S_{4}, S_{5}, S_{6}$ respectively. $E_{b}$ is modulus of elasticity for bellows. Figure 5 shows the metal expansion bellows under consideration in this paper.

\section{Numerical Simulation}

In order to perform numerical simulation, it is necessary to develop solid model of metal expansion bellows. Hence metallic expansion bellows is first modeled in Creo2.0 as shown in Figure 6, which is latest CAD software and makes modeling easy and user friendly. The model is then transferred in IGES format and geometry is imported for analysis to Ansys14.0 software. Then metal expansion bellows is analyzed in Ansys14.0 software.

4.1. Finite Element Procedure and Mesh Generation. Numerical simulation includes three stages of analysis as shown in Figure 7. First is preprocessing which involves modeling, geometric clean-up, element property definition, and meshing. Second step is solution of problem, which involves applying

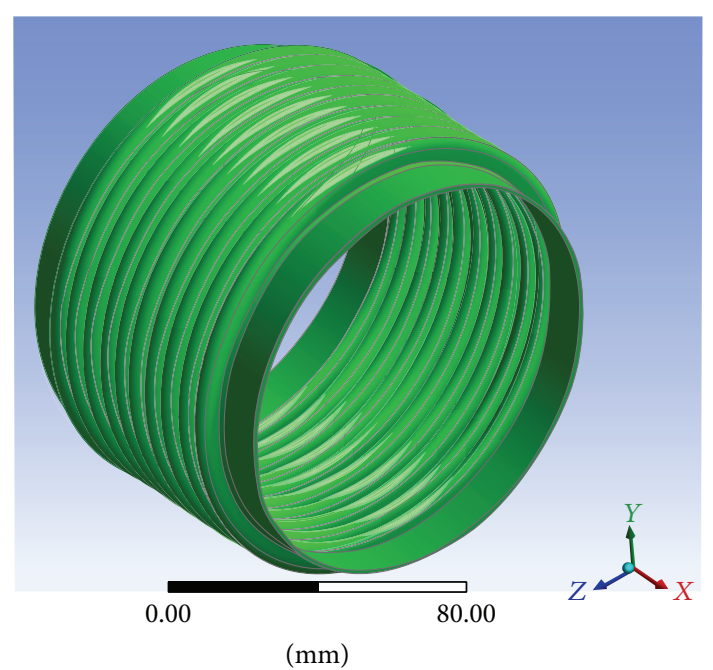

FIGURE 6: Solid model of metal expansion bellows.

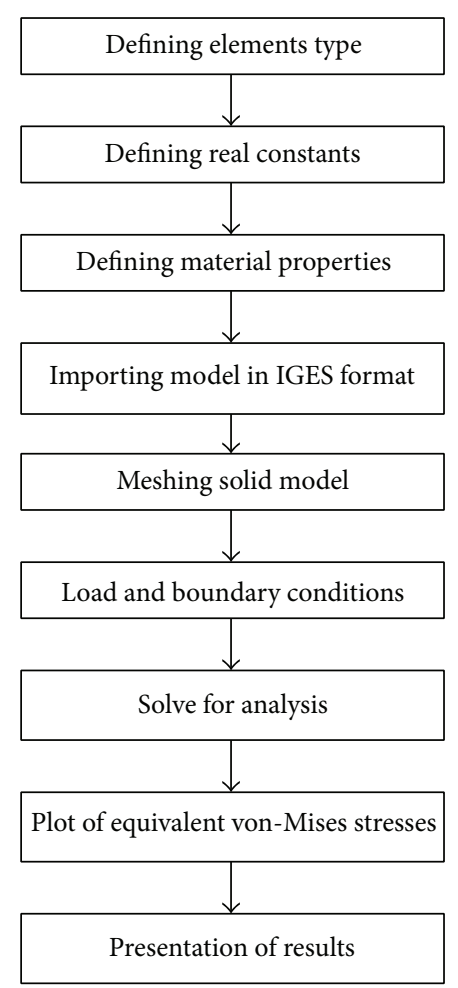

FIgURE 7: Stages of analysis.

boundary conditions on the model and then solution. Third step is postprocessing, which involves analyzing the results plotted with different parameters like stresses and deformation. The objective in creating a solid model is to mesh that model with nodes and elements. After completing the solid model, set element attributes and establishing meshing controls, which turn the Ansys program to generate the finite element mesh. For defining the elements attributes, the user has to select the correct element type. 


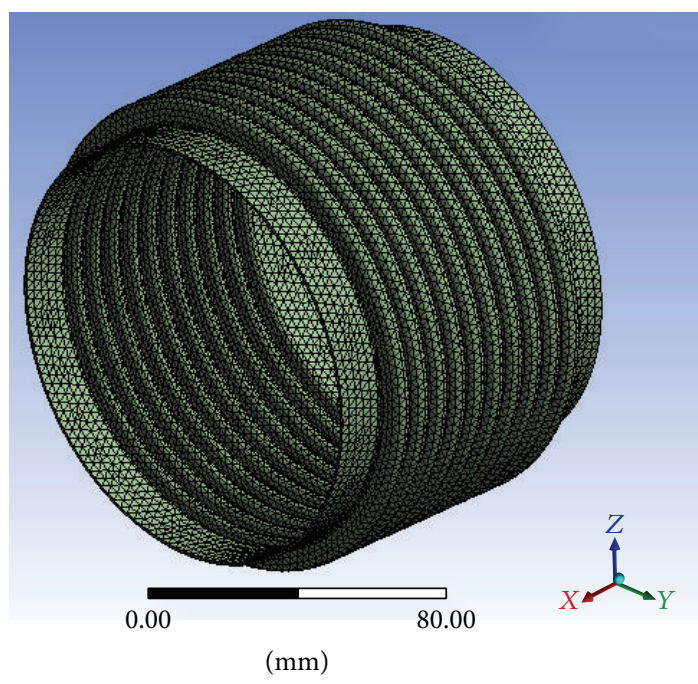

FIGURE 8: Meshed model of metal expansion bellows.

Figure 8 shows the meshed model of metal expansion bellows. In this work, structural solid element 20 node plane 183 element was used as element type. Elastic analyses were carried out on full convolutions of the bellows with axisymmetric model. The computational domain is divided into 10 elements in thickness and 200 elements in length. Therefore, the model with elements $10 \times 200$ is used in all analyses. In the present analysis, a U-shaped bellow named VLC Shell Dia. $129 \mathrm{~mm}$ is picked. The bellows inside diameter is $131 \mathrm{~mm}$ with outside diameter of $147 \mathrm{~mm}$, thickness of $0.9 \mathrm{~mm}$, pitch of $8.00 \mathrm{~mm}$, and height of the convolution is $8.00 \mathrm{~mm}$. The bellows is made of stainless steel SA-240 321 with the modulus of elasticity of $195 \mathrm{GPa}$ and Poisson's ratio of 0.3 . In this work, the internal pressure in applied by applying the constraints.

\section{Results and Discussions}

5.1. Numerical Validations. Comparison test is performed for verification of the results obtained by numerical method. For the given solid element, FEM stresses are evaluated. The circumferential membrane stress at bellows tangent, intermediate and end convolution membrane stress, meridional membrane stress, and meridional bending stress due to internal pressure of $\mathrm{U}$-shaped bellows are calculated. The applied internal pressures are $1 \mathrm{MPa}, 1.12 \mathrm{MPa}, 1.5 \mathrm{MPa}$, and $2 \mathrm{MPa}$, respectively. In Table 2 , the results obtained from analytical approach and numerical simulations are presented. The meridional membrane stress and meridional bending stress for various internal pressures are presented in Table 2. After comparing the results, it is observed that the obtained stresses by two approaches for $\mathrm{U}$-shaped bellows are in good agreement and show very closed match.

5.2. Comparison of Induced Design and Simulated Stresses of Metal Expansion Bellows. In the present work, numerical values of stresses are used for evaluation of characteristics of metallic bellows. Initially, the circumferential membrane
TABLE 2: Analytic and FEA stresses due to internal pressure.

\begin{tabular}{lccccc}
\hline \multirow{2}{*}{ Stress } & \multirow{2}{*}{ Source } & \multicolumn{4}{c}{ Internal pressure (MPa) } \\
& & 1 & 1.12 & 1.5 & 2 \\
\hline \multirow{2}{*}{$S_{1}$} & ASME & 73.26 & 82.05 & 109.89 & 146.52 \\
& FEA & 43.83 & 53.02 & 70.26 & 80.53 \\
\hline \multirow{2}{*}{$S_{2 I}$} & ASME & 31.28 & 35.03 & 46.92 & 62.56 \\
& FEA & 34.55 & 32.12 & 48.63 & 57.67 \\
\hline \multirow{2}{*}{$S_{2 E}$} & ASME & 48.52 & 54.35 & 81.52 & 163.05 \\
& FEA & 42.36 & 34.44 & 61.46 & 86.41 \\
\hline \multirow{2}{*}{$S_{3}$} & ASME & 4.89 & 5.14 & 6.56 & 9.19 \\
& FEA & 30.39 & 33.26 & 45.41 & 61.85 \\
\hline \multirow{2}{*}{$S_{4}$} & ASME & 82.18 & 92.04 & 123.28 & 164.37 \\
& FEA & 33.12 & 31.73 & 47.48 & 54.68 \\
\hline
\end{tabular}

stress is simulated for various internal pressures. As per the requirement, the internal pressures selected were $1 \mathrm{MPa}$, 1.12 MPa, 1.5 MPa, and 2 MPa, respectively. Figure 9 shows comparison of circumferential membrane stress induced in bellows tangent due to internal pressure of $2 \mathrm{MPa}$. Similar plots are obtained for various pressures as $1 \mathrm{MPa}, 1.12 \mathrm{MPa}$, and 1.5 MPa. Comparison of different stresses for various pressures is explained in Figures 10-14. From Figure 10, it is seen that the circumferential membrane stress obtained by both approaches shows considerable variation in induced stress, but, as per design criterion, this is within acceptable agreement. This is an important membrane stress that runs circumferentially around the bellows. For safety, the value must be lower than the allowable stress for the bellows material multiplied by the bellows longitudinal weld joint efficiency. Figure 11 shows variation of intermediate convolution circumferential membrane stress due to internal pressure. From Figure 11, it is observed that the intermediate convolution circumferential membrane stress obtained by both approaches shows very closed match. This means that the stresses obtained by both approaches are in good agreement.

From Figure 12, it is seen that the end convolution circumferential membrane stress obtained by both approaches shows considerable variation as pressure varies from $1.12 \mathrm{MPa}$ to $2 \mathrm{MPa}$, but as per design criterion this is within acceptable limit. The end convolution circumferential membrane stress obtained by both approaches shows much closed match for pressure of $1 \mathrm{MPa}$. This means that the stress obtained by both approaches is in good agreement.

Figure 13 shows the variation of meridional membrane stress due to internal pressure. It is seen that the meridional membrane stress obtained by both approaches shows considerable variation in induced stresses, but as per design criterion this is within acceptable limit. From Figure 13, it is observed that the calculated meridional membrane stress as per ASME standard almost remains constant as pressure varies from $1 \mathrm{MPa}$ to $2 \mathrm{MPa}$, but the simulated meridional membrane stress increases significantly as pressure increases from $1 \mathrm{MPa}$ to $2 \mathrm{MPa}$. 

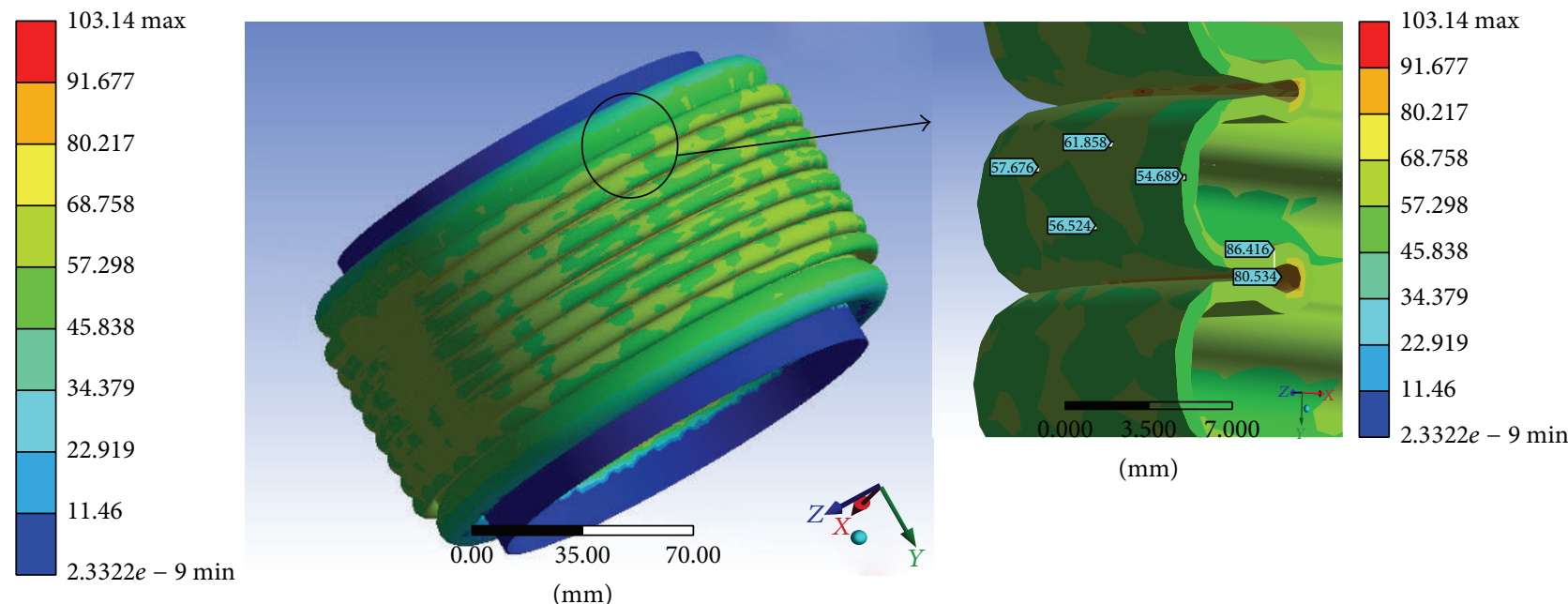

FIGURE 9: Simulated model of metal expansion bellows for internal pressure of $2 \mathrm{MPa}$.

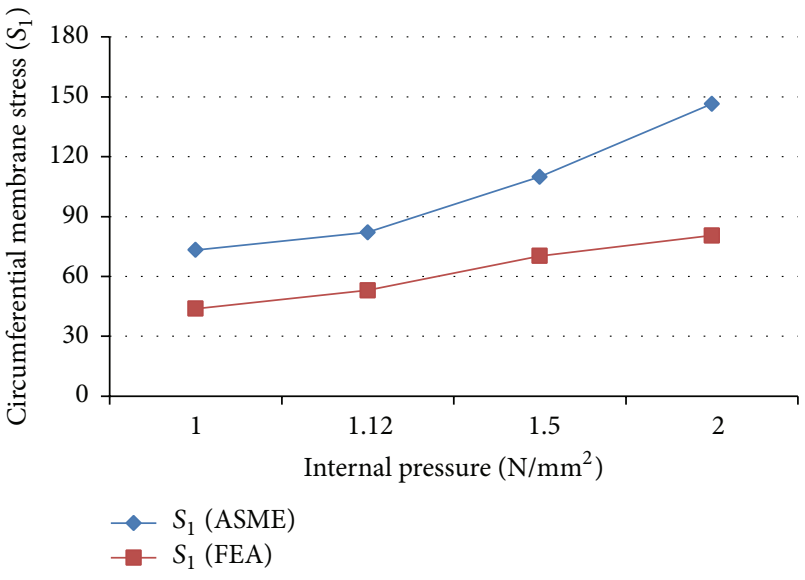

FIGURE 10: Circumferential membrane stresses in bellows tangent.

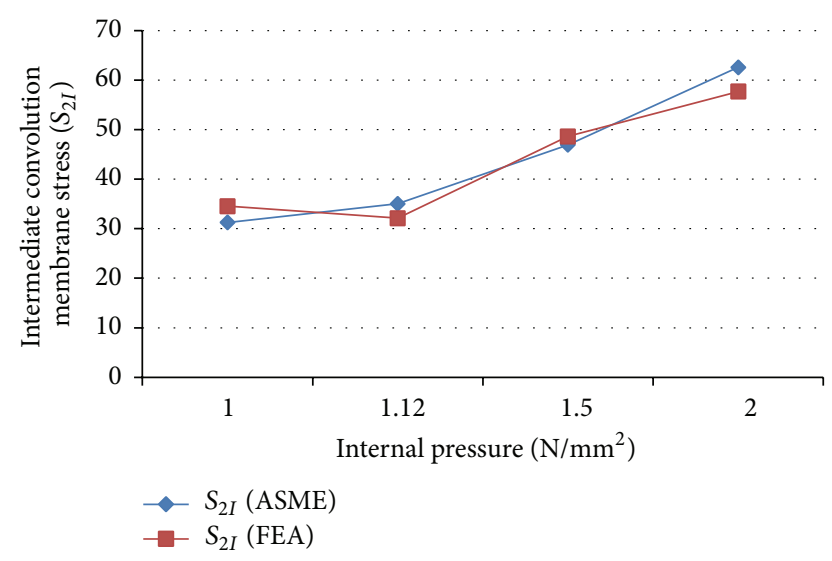

FIGURE 11: Intermediate convolution circumferential membrane stress.

Figure 14 shows the variation of meridional bending stress due to internal pressure. It is seen that the meridional bending stress obtained by both approaches shows considerable variation in induced stresses, but as per design criterion this

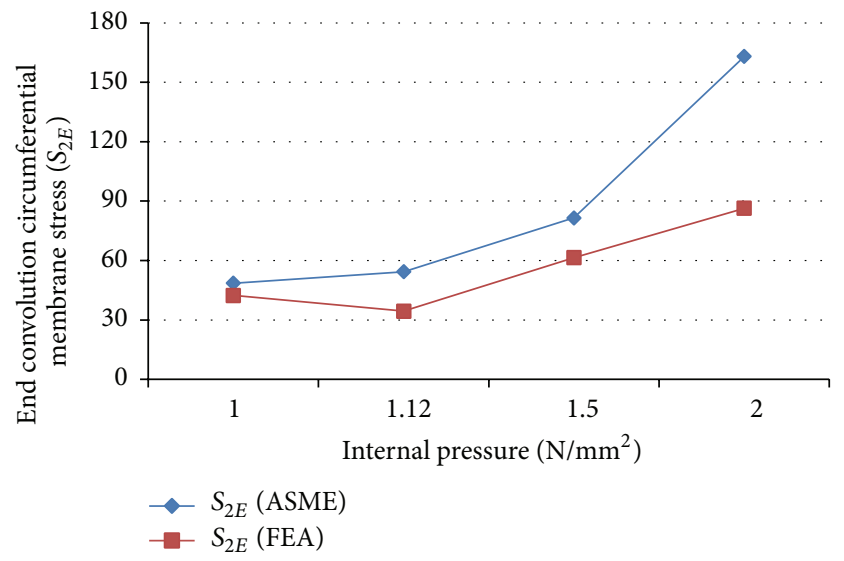

FIGURE 12: End convolution circumferential membrane stress.

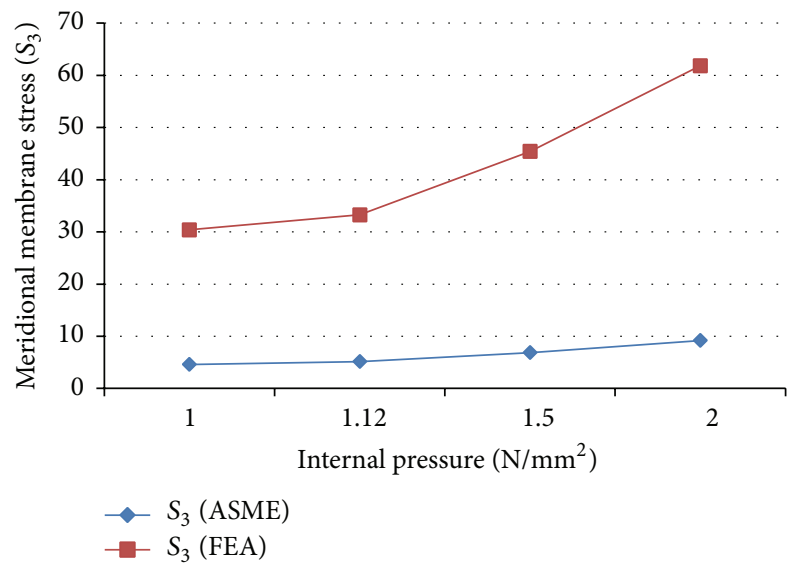

FIGURE 13: Meridional membrane stress.

is within acceptable limit. From Figure 14 again, it is found that the calculated meridional bending stress as per ASME standard almost remains constant as pressure varies from $1 \mathrm{MPa}$ to $2 \mathrm{MPa}$, but the simulated meridional bending stress 


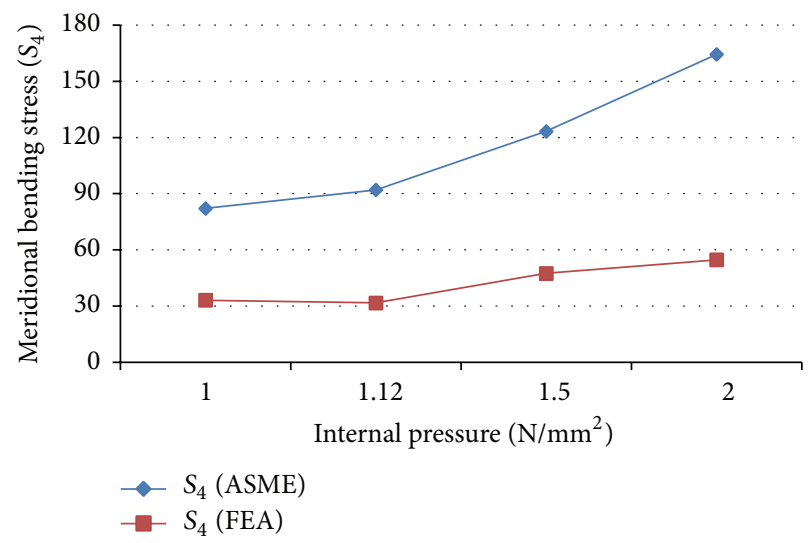

FIGURE 14: Meridional bending stress.
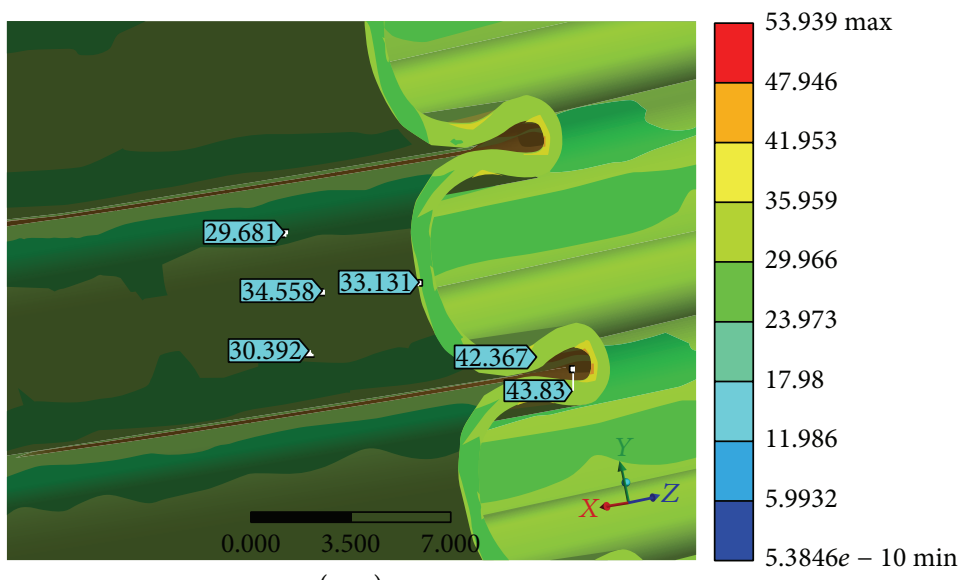

$(\mathrm{mm})$

FIgURE 15: Stress distribution due to internal pressure of $1 \mathrm{MPa}$.

increases significantly as pressure increases from $1 \mathrm{MPa}$ to $2 \mathrm{MPa}$.

5.3. Stress Distribution due to Internal Pressure. The internal pressure varying from $1 \mathrm{MPa}$ to $2 \mathrm{MPa}$ was applied on considered metal expansion bellows with boundary condition, as no (fixed) displacement of the six sides of the bellows. Figures 15-18 show stress distribution in the metal expansion bellows under consideration for internal pressure of $1 \mathrm{MPa}, 1.12 \mathrm{MPa}$, $1.5 \mathrm{MPa}$, and $2 \mathrm{MPa}$.

\section{Conclusions}

In this paper, analytical and simulation study for characteristics of U-shaped metallic bellows is conducted. The results obtained as per ASME standards are compared with the FEA for stress distribution. The design stresses and distributions are compared for U-shaped bellows. The main conclusion is that the most destructive stress in bellows due to internal pressure is meridional bending stress and circumferential membrane stress. The circumferential membrane stress is an important membrane stress that runs circumferentially around the bellows. For bellows functional safety, this value must be lower than the allowable stress.

\section{Notations}

$S: \quad$ Bellows design allowable stress

$S_{a}$ : Bellows ambient allowable stress

$S_{y}: \quad$ Bellows yield stress

$E_{b}$ : Bellows elastic modulus at design temperature

$E_{o}$ : Bellows elastic modulus at ambient temperature

$v_{b}$ : Poisson's Ratio

$N_{\text {req }}$ : Design cycle life, required number of cycles

$P$ : Design internal pressure

$D_{B}$ : Bellows inside diameter

$w$ : Convolution depth

Q: Convolution pitch

$\Delta Q$ : Expansion joint opening per convolution

$N$ : Total number of convolutions

$t$ : Nominal thickness of one ply

$n$ : $\quad$ Total number of plies

$L_{T}$ : End tangent length

$K_{g}$ : Fatigue strength reduction factor.

\section{Conflict of Interests}

The authors declare that there is no conflict of interests regarding the publication of this paper. 


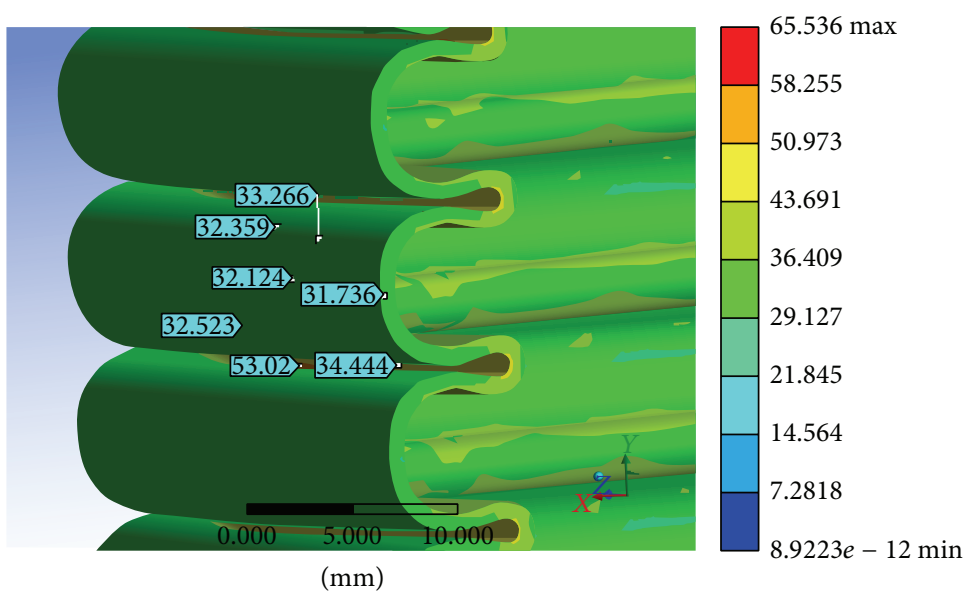

FIGURE 16: Stress distribution due to internal pressure of 1.12 MPa.

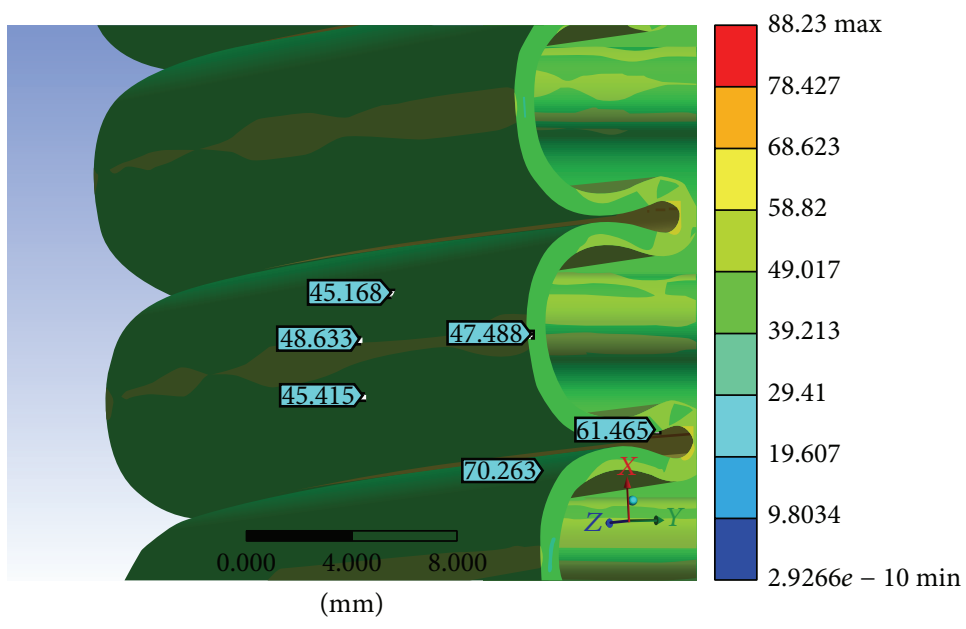

FIGURE 17: Stress distribution due to internal pressure of 1.5 MPa.
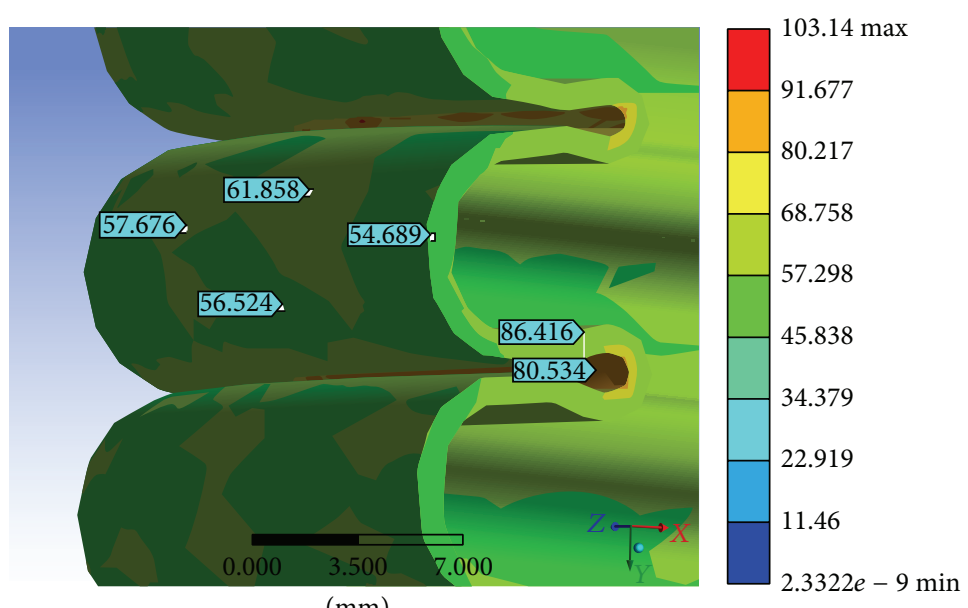

(mm)

FIGURE 18: Stress distribution due to internal pressure of $2 \mathrm{MPa}$. 


\section{Acknowledgment}

Authors would like to thank Mr. Umesh Ubarhande, Senior Manager (R\&D, PEM) of Alfa Laval India Pvt. Ltd., Pune, for helping them in formulating the problem and providing the necessary input and guidance to achieve the objective.

\section{References}

[1] ASME, "ASME boiler and pressure vessel code-section VIII, division 1," in Appendix 26-Pressure Vessel and Heat Exchanger Joints, ASME, New York, NY, USA, 2000.

[2] EJMA, Standards of Expansion Joint Manufacturers Association, Expansion Joint Manufacturers Association, New York, NY, USA, 9th edition, 2008.

[3] H. Shaikh, G. George, and H. S. Khatak, "Failure analysis of an AM 350 steel bellows," Engineering Failure Analysis, vol. 8, no. 6, pp. 571-576, 2001.

[4] G. I. Broman, A. P. Jönsson, and M. P. Hermann, "Determining dynamic characteristics of bellows by manipulated beam finite elements of commercial software," International Journal of Pressure Vessels and Piping, vol. 77, no. 8, pp. 445-453, 2000.

[5] T. Li, "Effect of the elliptic degree of $\Omega$-shaped bellows toroid on its stresses," International Journal of Pressure Vessels and Piping, vol. 75, no. 13, pp. 951-954, 1998.

[6] C. Becht IV, "Fatigue of bellows, a new design approach," International Journal of Pressure Vessels and Piping, vol. 77, no. 13, pp. 843-850, 2000.

[7] G. H. Faraji, M. M. Mashhadi, and V. Norouzifard, "Evaluation of effective parameters in metal bellows forming process," Journal of Materials Processing Technology, vol. 209, no. 7, pp. 3431-3437, 2009.

[8] G. H. Faraji, M. K. Besharati, M. Mosavi, and H. Kashanizadeh, "Experimental and finite element analysis of parameters in manufacturing of metal bellows," The International Journal of Advanced Manufacturing Technology, vol. 38, no. 7-8, pp. 641648, 2008.

[9] B. H. Kang, M. Y. Lee, S. M. Shon, and Y. H. Moon, "Forming various shapes of tubular bellows using a single-step hydroforming process," Journal of Materials Processing Technology, vol. 193, no. 1-3, pp. 1-6, 2007.

[10] H.-W. Kang, I. H. Lee, and D.-W. Cho, "Development of a microbellows actuator using micro-stereolithography technology," Microelectronic Engineering, vol. 83, no. 4-9, pp. 1201-1204, 2006.

[11] V. Jakubauskas and D. S. Weaver, "Transverse natural frequencies and flow induced vibrations of double bellows expansion joints," Journal of Fluids and Structures, vol. 13, no. 4, pp. 461479, 1999.

[12] A. K. Jha, V. Diwakar, and K. Sreekumar, "Stress corrosion cracking of stainless steel bellows of satellite launch vehicle propellant tank assembly," Engineering Failure Analysis, vol. 10, no. 6, pp. 699-709, 2003.

[13] Y. Z. Zhu, H. F. Wang, and Z. F. Sang, "The effect of environmental medium on fatigue life for $\mathrm{u}$-shaped bellows expansion joints," International Journal of Fatigue, vol. 28, no. 1, pp. 1-5, 2006.

[14] G. Wang, K. F. Zhang, D. Z. Wu, J. Z. Wang, and Y. D. Yu, "Superplastic forming of bellows expansion joints made of titanium alloys," Journal of Materials Processing Technology, vol. 178 , no. $1-3$, pp. $24-28,2006$.
[15] S. W. Lee, "Study on the forming parameters of the metal bellows," Journal of Materials Processing Technology, vol. 130-131, pp. 47-53, 2002. 

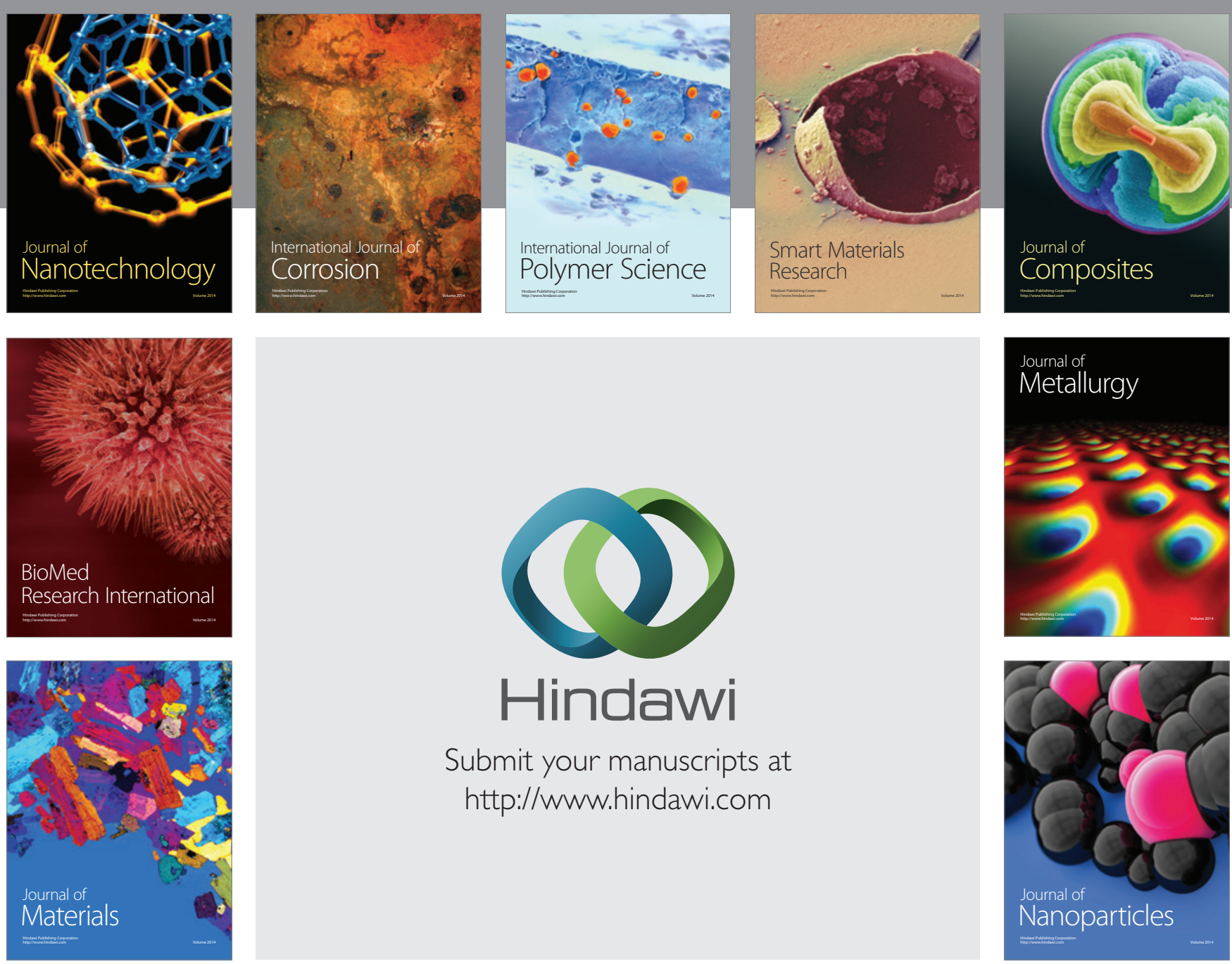

Submit your manuscripts at http://www.hindawi.com
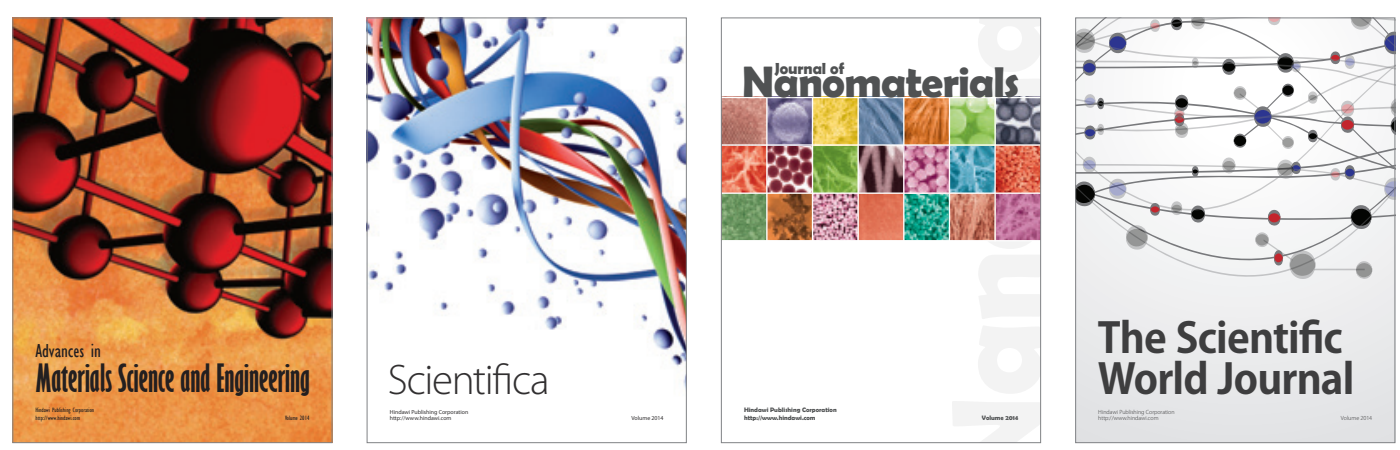

\section{The Scientific World Journal}
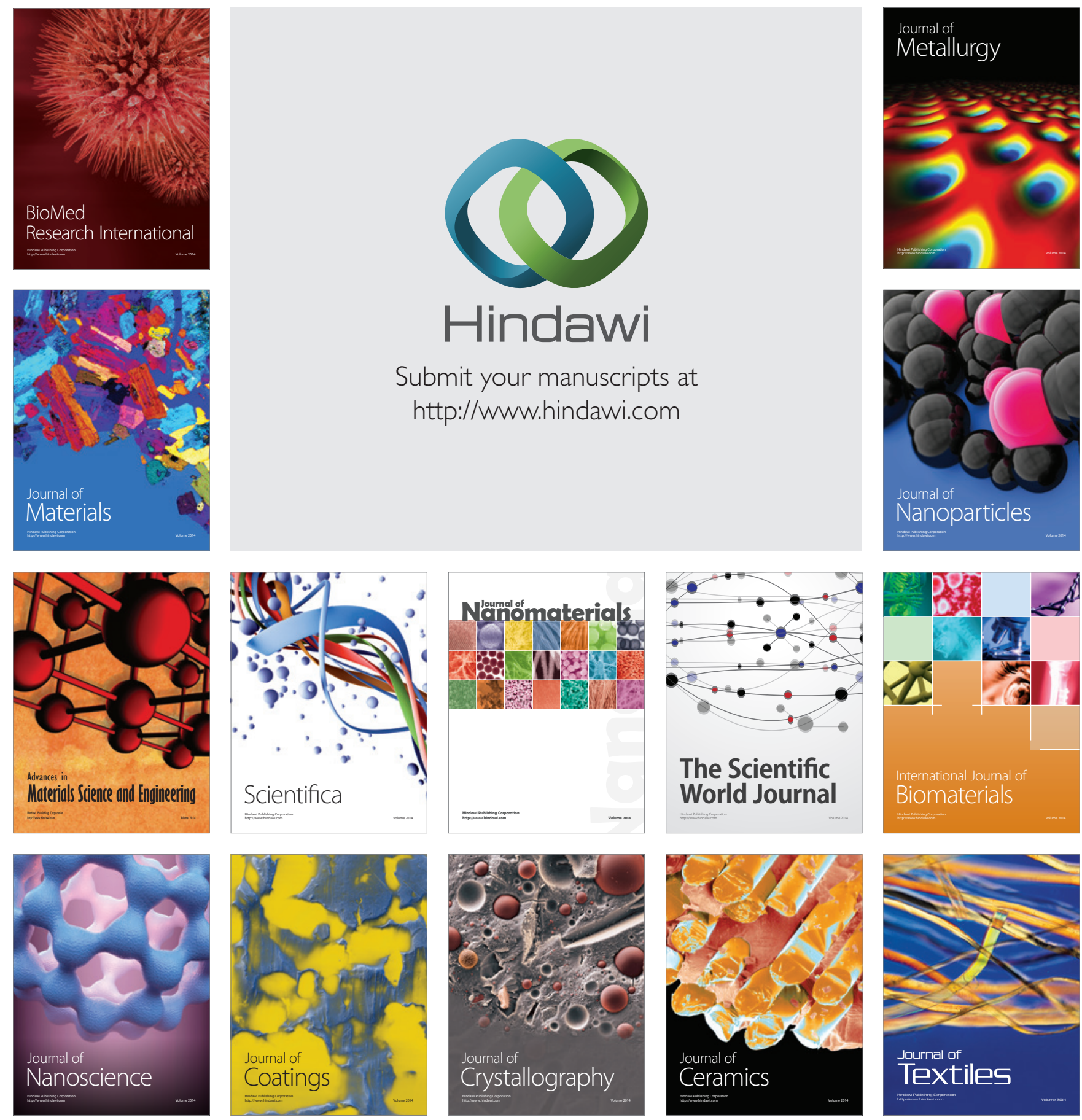